\title{
Crystal structure of Usutu virus envelope protein in the pre-fusion state
}

Zimin Chen ${ }^{1}$, Fei Ye ${ }^{1}$, Sheng Lin ${ }^{1}$, Fanli Yang ${ }^{1}$, Yanwei Cheng ${ }^{1}$, Yu Cao ${ }^{1,2}$, Zhujun Chen ${ }^{1}$ and Guangwen Lu ${ }^{1 *}$

\begin{abstract}
Background: Usutu virus (USUV) is a mosquito-born flavivirus that can infect multiple avian and mammalian species. The viral surface envelope (E) protein functions to initiate the viral infection by recognizing cellular receptors and mediating the subsequent membrane fusion, and is therefore a key virulence factor involved in the pathogenesis of USUV. The structural features of USUV-E, however, remains un-investigated thus far.

Findings: Using the crystallographic method, we determined the structure of USUV-E in the pre-fusion state at 2.0 angstrom. As expected, the overall fold of USUV-E, with three $\beta$-barrel domains (DI, DII, and DIII), resembles those of other flaviviral E proteins. In comparison to other pre-fusion E structures, however, USUV-E exhibits an apparently enlarged inter-domain angle between DI and DIl, leading to a more extended conformation. Using our structure and other reported pre-fusion E structures, the DI-DII domain-angle difference was analyzed in a pairwise manner. The result shows a much higher degree of variations for USUV-E, indicating the potential for remarkable DI-DII domain angle plasticity among flaviviruses.
\end{abstract}

Conclusion: We report the crystal structure of USUV-E and show that its pre-fusion structure has an enlarged DI-DII domain-angle which has not been observed in other reported flaviviral E-structures.

Keywords: Usutu virus, Envelope, Crystal structure, Pre-fusion state, Domain-angle difference

\section{Introduction}

The mosquito-born Usutu virus (USUV) was first identified in 1959 in South Africa [2, 32, 53]. Phylogenetically, the virus is closely related to Japanese encephalitis virus (JEV), West Nile virus (WNV) and Murray Valley encephalitis virus (MVEV), and is therefore categorized into the JEV serocomplex within the Flavivirus genus of the Flaviviridae family [9, 23, 54]. The natural life cycle of USUV involves circulation of the virus between mosquitos and birds such that mosquitos act as vectors and birds as amplifying hosts $[8,45,48,49]$. In addition to avian species, the virus can also, in incidental cases, be transmitted via mosquito bite to other species including horses, rodents and even humans [5, $10,46]$. Although human cases of USUV infection remain largely asymptomatic, the USUV-related severe diseases such as fever, rash, and meningoencephalitis

\footnotetext{
* Correspondence: lugw@scu.edu.cn

${ }^{1}$ West China Hospital Emergency Department (WCHED), State Key Laboratory of Biotherapy, West China Hospital, Sichuan University, Chengdu 610041,

Sichuan, China

Full list of author information is available at the end of the article
}

have also been reported $[6,17,42]$. Furthermore, in laboratory infected mice, the virus could be detected in multiple organs and tissues, including brain, heart, liver, kidney, lung, and etc., demonstrating the pathogenic potential of the virus in mammals $[1,33]$. It is notable that several serological surveillance studies have demonstrated the low-prevalence circulation of USUV in the European population, raising the risk of potential USUV outbreaks in humans [19].

As with other flaviviruses, USUV is an enveloped virus which contains a positive-sense, single-stranded RNA genome. This genome encodes a large polyprotein precursor that would be later, via virus-encoded and host proteases, proteolytically processed into three structural (including core (C), pre-membrane (prM), and envelope (E)) and eight non-structural (NS1, NS2A, NS2B, NS3, NS4A, $2 \mathrm{~K}, \mathrm{NS} 4 \mathrm{~B}$, and NS5) proteins [3]. Of these, the surface-located $E$ protein recognizes cellular receptor/(s) and mediates subsequent fusion between the virus envelope and the lipid bilayer of host cells, and is therefore a key player initiating the viral infection [42]. Structural investigations on 
flavivirus $\mathrm{E}$ protein have revealed a strand-dominated fold with three $\beta$-barrel domains [13]. Domain I (DI) is centrally located in the molecule. It connects on one side to domain II (DII) via four polypeptide chains and on the other to domain III (DIII) with a single polypeptide linker. Unlike DI which is overall of globular shape, DII is an elongated structure. A highly hydrophobic fusion peptide is located in this domain, residing at its distal end. DIII folds into an immunoglobulin (Ig)-like structure, and is believed to be involved in receptor binding and also the major target of neutralizing antibodies. In mature virions, E protein assembles, in a "head-to-tail" mode, into pre-fusion dimers, shedding the fusion peptide from premature exposure [27]. During viral entry, E protein would experience large acidic-pH-induced structural re-arrangements via motions of the DI-DII and DI-DIII domain hinges, which would finally lead to the formation of post-fusion trimers and the simultaneous exposure of its fusion peptide for membrane fusion [7]. The functional importance of $\mathrm{E}$ in the flaviviral life cycle makes the protein a favorite target for structural studies. While the $\mathrm{E}$ structures of multiple flaviviruses, including dengue virus (DENV), JEV, WNV, Zika virus (ZIKV), Tickborn encephalitis virus (TBEV), and etc., have been reported [4, 11, 13, 20, 26-29, 34, 39-41, 51, 57], the structural features of USUV $\mathrm{E}$ protein (USUV-E) remains elusive.

In this study, we reported the atomic crystal structure of USUV-E in its pre-fusion state. As expected, USUV-E also folds into three $\beta$-barrel domains and exhibits an overall extended conformation. Despite that only a single USUV-E molecule is present in the crystallographic asymmetric unit, a head-to-tail dimer similar to other flaviviral $\mathrm{E}$ structures could be observed via symmetry operations. While the overall USUV-E structure resembles those of other flaviviral E proteins, its DII connects to DI in a more extended manner, leading to an apparently enlarged DI-DII inter-domain angle. Via structural comparisons, we further showed that USUV-E, among representative pre-fusion E structures, exhibits a much higher degree of domain-angle variations between DI and DII, which we believe represents potential evidence for a remarkable DI-DII angle-plasticity among flaviviruses.

\section{Materials and methods}

\section{Gene construction}

The coding region for ectodomain residues 1-409 of the envelope protein from USUV (GeneBank: YP_164819) was synthesized by the GENEWIZ corporation and cloned into the bacterial expression vector pET21a with a C-terminal $6 \times$ His-tag by restriction digestion sites of Nde I and XhoI.

\section{Protein expression and inclusion body preparation}

For protein expression, the recombinant plasmid was transformed into E. coli BL21 (DE3) cells, and a single colony was picked up and inoculated into $10 \mathrm{ml} \mathrm{LB}$ medium for overnight growth. The subsequent cell culture were then transformed into $1 \mathrm{~L}$ of fresh $\mathrm{LB}$ medium at the volume ratio of $1: 100$ and allowed to grow at $37^{\circ} \mathrm{C}$ until the $\mathrm{OD}_{600}$ reached 0.6-0.8. Then, isopropylthiogalactoside (IPTG) was added into the culture at $1 \mathrm{mM}$ to induce the protein expression. After induction at $37^{\circ} \mathrm{C}$ for $6 \mathrm{~h}$, the cells were collected and analyzed by SDS-PAGE.

For inclusion bodies preparation, the harvested cells were lysed by sonication in a buffer consisting of 20 $\mathrm{mM}$ Tris- $\mathrm{HCl}, \mathrm{pH} 8.0$, and $150 \mathrm{mM} \mathrm{NaCl}$. Next, the lysate was centrifuged at $15,000 \mathrm{~g}$, and the pellet containing the protein inclusion bodies was washed three times with $50 \mathrm{ml}$ of wash buffer $(50 \mathrm{mM}$ Tris- $\mathrm{HCl}, \mathrm{pH}$ 8.0, $0.5 \%$ Triton X-100, $300 \mathrm{mM} \mathrm{NaCl}, 10 \mathrm{mM}$ EDTA, $10 \mathrm{mM}$ DTT). Then, the purified inclusion bodies were re-suspended in $40 \mathrm{ml}$ of re-suspension buffer $(50 \mathrm{mM}$ Tris- $\mathrm{HCl}, \mathrm{pH} 8.0,100 \mathrm{mM} \mathrm{NaCl}, 10 \mathrm{mM}$ EDTA, 10 $\mathrm{mM}$ DTT) to remove the residual Triton X-100. After centrifugation at $15,000 \mathrm{~g}$, the final inclusion-body pellet was solubilized in dissolution buffer $(6 \mathrm{M} \mathrm{Gua-HCl}$, $10 \%$ glycerol, $50 \mathrm{mM}$ Tris- $\mathrm{HCl}, \mathrm{pH} 8.0,100 \mathrm{mM} \mathrm{NaCl}$, $10 \mathrm{mM}$ EDTA, $10 \mathrm{mM}$ DTT) at $30 \mathrm{mg} / \mathrm{ml}$.

\section{Protein refolding and purification}

The USUV-E protein was expressed as inclusion bodies and then refolded in vitro using the diluted refolding method [25] with some modifications. Briefly, aliquots of inclusion bodies were diluted dropwise into a refolding buffer consisting of $100 \mathrm{mM}$ Tris- $\mathrm{HCl}, \mathrm{pH}$ 8.0, 600 $\mathrm{mM} \mathrm{L}$-Arg $\mathrm{HCl}, 2 \mathrm{mM}$ EDTA, $5 \mathrm{mM}$ reduced glutathione, $0.5 \mathrm{mM}$ oxidized glutathione, and $10 \%$ glycerol, and then refolded overnightat $4{ }^{\circ} \mathrm{C}$. Subsequently, the refolded protein was concentrated using an Amicon Stirred Cell (UFSC40001) concentrator with $10 \mathrm{kDa}$ cut off membrane and then adjusted to $20 \mathrm{mM}$ Tris- $\mathrm{HCl}, \mathrm{pH} 8.0,150 \mathrm{mM} \mathrm{NaCl}$, and $5 \%$ glycerol. Then the refolded E protein was further purified in an AKTA Pure System by gel filtration on a Superdex 200 increase 10/300 GL column (GE Healthcare).

\section{Crystallization, data collection, and structure determination}

The purified USUV-E protein was concentrated to $8 \mathrm{mg} /$ ml. The crystallization trials were performed with $1 \mu \mathrm{l}$ protein mixing with $1 \mu \mathrm{l}$ reservoir solution and then equilibrating against $70 \mu \mathrm{l}$ reservoir solution by sitting drop vapor diffusion at $18{ }^{\circ} \mathrm{C}$. The initial crystallization screening was performed using the commercially-available kits (Hampton Research and Molecular Dimensions). 
Conditions that can support crystal growth were then optimized with the hanging-drop vapor-diffusion method. High-quality crystals were finally obtained under a condition composed of 0.1 M HEPES, pH 7.5, 10\% w/v Polyethylene glycol 8000, and 8\% v/v Ethylene glycol. Diffraction data were collected at Shanghai Synchrotron Radiation Facility (SSRF) BL18U1. For data collection, all crystals were cryo-protected by briefly soaking in reservoir solution supplemented with $20 \%(\mathrm{v} / \mathrm{v})$ glycerol before flash-cooling in liquid nitrogen. The collected data were processed using HKL2000 [36].

The structure of USUV-E was determined by the molecular replacement method using Phaser [16] with the structure of WNV-E protein (PDB: 2hg0) as the search model. The atomic model was completed with Coot [14, 15]. Rounds of refinement was performed with REFMAC5 [31], and finally with Phenix [47, 58]. The final model was assessed with PROCHECK [24]. Final statistics for data collection and structure refinement are presented in Table 1. All structural figures were generated using PyMOL (http://pymol.sourceforge.net). The USUV-E structure has been deposited into the Protein Data Bank with a PDB code of 6A0P.

\section{Results and discussion}

USUV-E, with a canonical type I transmembrane topology, contains a large N-terminal ecto-domain (residues F1-R450) (Fig. 1a). To gain insight into the structural features of USUV-E, the ecto-domain region of the protein spanning amino acids F1-A406 was first engineered to include a C-terminal 6xHis tag and then expressed in E. coli. Following several previous reports on flaviviral E-preparations [13, 20, 27], the resultant USUV-E protein was initially expressed in the form of inclusion bodies (Fig. 1b), and subsequently refolded and further purified to homogeneity by gel filtration chromatography (Fig. 1c).

Via crystallization screening, crystals of USUV-E that can diffract to $2.0 \AA$ were successfully obtained via the hanging-drop vapor-diffusion method. The structure was solved by molecular replacement and finally refined to Rwork $=0.214$ and Rfree $=0.247$, respectively (Table 1). Within the crystallographic asymmetric unit, a single USUV-E molecule was present, and clear electron densities were successfully traced for USUV-E amino acids F1-R406 as well as for four terminal His residues of the fusion tag.

As expected, USUV-E also folds into three domains (DI, DII, and DIII), showing an extended and a $\beta$-dominated structure (Fig. 2a). DI is composed of nine $\beta$-strands $\left(\mathrm{A}_{0}-\mathrm{I}_{0}\right)$, forming a compact barrel structure. One helix $(\alpha 1)$ is present in DI, sterically situating in the vicinity of the $\mathrm{A}_{0} \mathrm{C}_{0} \mathrm{D}_{0} \mathrm{E}_{0} \mathrm{~F}_{0}$ sheet and also of the molecule $\mathrm{N}$-terminus (Fig. 2a). It is notable that this helix is also observed in the structures of $\mathrm{E}$ proteins
Table 1 Data collection and refinement statistics

\begin{tabular}{|c|c|}
\hline \multicolumn{2}{|l|}{ Data collection } \\
\hline Space group & $P 2_{1} 2_{1} 2_{1}$ \\
\hline \multicolumn{2}{|l|}{ Cell dimensions } \\
\hline$a, b, c(\AA)$ & $35.04,104.34,115.58$ \\
\hline$a, \beta, \gamma\left(^{\circ}\right)$ & $90^{\circ}, 90^{\circ}, 90^{\circ}$ \\
\hline Wavelength $(\AA)$ & 0.9793 \\
\hline Resolution $(\AA)^{a}$ & $50.0-2.0(2.07-2.00)$ \\
\hline Rmerge $^{a, b}$ & $0.13(0.808)$ \\
\hline$|/ \sigma|^{a}$ & $13.51(2.73)$ \\
\hline Completeness (\%) & $99.6(98.80)$ \\
\hline Redundancy ${ }^{a}$ & $5.5(4.9)$ \\
\hline Total reflections & 161,936 \\
\hline Unique reflections & 29,488 \\
\hline \multicolumn{2}{|l|}{ Refinement } \\
\hline Resolution $(\AA)$ & $30.99-2.0$ \\
\hline Rwork/Rfree ${ }^{c}$ & $0.214 / 0.247$ \\
\hline \multicolumn{2}{|l|}{ No. of atoms } \\
\hline Protein & 3111 \\
\hline Water & 232 \\
\hline \multicolumn{2}{|l|}{ B-factors } \\
\hline Protein & 39 \\
\hline Water & 42.5 \\
\hline \multicolumn{2}{|l|}{ r.m.s.d. } \\
\hline Bond lengths ( $\AA$ ) & 0.018 \\
\hline Bond angles $\left(^{\circ}\right)$ & 1.64 \\
\hline \multicolumn{2}{|l|}{ Ramachandran plot ${ }^{d}$} \\
\hline Ramachandran favored (\%) & $98 \%$ \\
\hline Ramachandran allowed (\%) & $2 \%$ \\
\hline Ramachandran outliers (\%) & 0 \\
\hline
\end{tabular}

${ }^{a}$ Values for the outmost resolution shell are given in parentheses

${ }^{\mathrm{b}}$ Rmerge $=\Sigma \mathrm{i} \Sigma \mathrm{hkl}|\mathrm{li}-\langle\mathrm{l}\rangle| / \Sigma \mathrm{i} \Sigma \mathrm{hklli}$, where li is the observed intensity and $\langle\mathrm{I}\rangle$ is the average intensity from multiple measurements

${ }^{\mathrm{c}}$ Rwork $=\Sigma||$ Fo $|-| \mathrm{Fc}|| / \Sigma \mid$ Fo $\mid$, where Fo and Fc are the structure-factor amplitudes from the data and the model, respectively. Rfree is the R factor for a subset $(5 \%)$ of reflections that was selected prior to refinement calculations and was not included in the refinement

${ }^{d}$ Ramachandran plots were generated by using the program MolProbity

from other JEV serocomplex members (eg. WNV and JEV) but not of other flaviviral E proteins (Fig. 2c-d). We also noted that this helix is, along the $\mathrm{E}$ protein sequence (Fig. 2e), located in the $\mathrm{E}_{0} \mathrm{~F}_{0}$ inter-strand loop (also called the glycan loop) where a glycosylation site locates. The USUV-E protein prepared in this study, however, lacks any glycosylation modifications at this site due to expression in E. coli. Nevertheless, when comparing our protein to a similarly eubacteria-yielded JEV protein without glycan decoration and an insectcell-generated WNV protein that contains glycan modifications, their structures revealed both well-aligned 

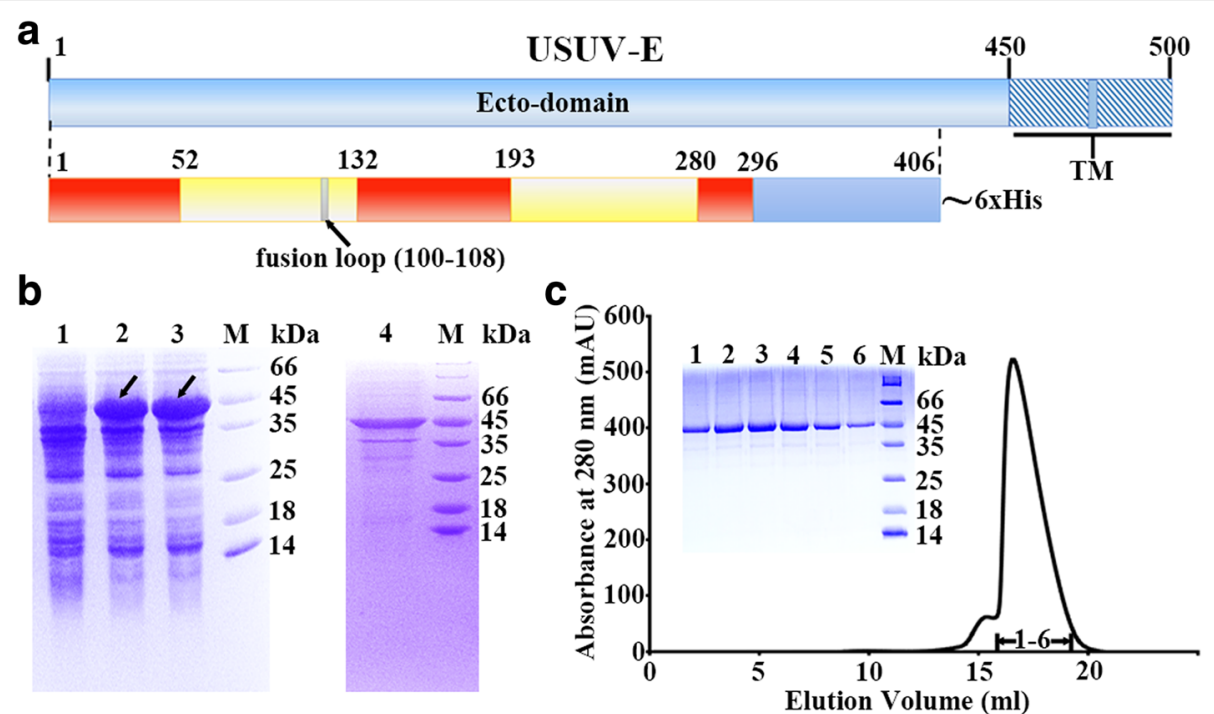

Fig. 1 Expression and purification of the USUV-E protein. a A schematic view of USUV-E. The ecto-domain and the transmembrane domains (TM) of the protein are indicated. For USUV-E preparation, its ecto-domain region spanning residues 1-406 was expressed as a fusion protein with a Cterminal 6 xHis tag. The three domains of this ecto-domain protein are highlighted in red, yellow, and blue, respectively, and the fusion loop is in grey. $\mathbf{b}$ Small-scale expression and inclusion-body extraction. The SDS-PAGE results are shown. Lane 1, un-induced; lane 2, induction with $0.2 \mathrm{mM}$ IPTG; lane 3, induction with $1 \mathrm{mM}$ IPTG; lane 4, the extracted inclusion bodies. The USUV-E protein was marked with arrows. c Purification of the refolded USUV-E protein by size exclusion chromatography. The separation chromatograph of the protein and the SDS-PAGE analyses of the pooled samples are shown

$\mathrm{E}_{0} \mathrm{~F}_{0}$ loops and the $\alpha 1$ helices (Fig. 2c). The formation of such a helix in the USUV, JEV, and WNV E proteins is therefore unlikely affected by the glycosylation status of this glycan loop. In light of the high conformationvariability observed for this glycan loop in other flaviviral E structures (Fig. 2d), we believe this extra $\alpha 1$ helix is likely a novel feature of the JEV serocomplex viruses. Sterically, DI is located in the center of the $\mathrm{E}$ molecule and is further flanked on one side by DII and on the other by DIII (Fig. 2a). DII consists of 8 strands $(\mathrm{a}-\mathrm{h})$ and 4 helices $(\alpha \mathrm{a}-\alpha \mathrm{d})$, exhibiting a rather extended conformation. This domain can be further divided into two subdomains (subdomain I and II). The latter directly connects to DI via four polypeptide linkers and is composed of a four-stranded (a, d, e, and f) anti-parallel $\beta$-sheet and three $\alpha$-helices $(\alpha b, \alpha c, \alpha d)$; while the former is located at the distal end of the molecule, showing a $\beta$-barrel fold with three long strands (b, c, and d) at the bottom and two small ones ( $g$ and h) on the top. The fusion peptide, with amino acids G100-F108 is residing in subdomain I. It is also noteworthy that the DII d strand, which is of great length, exhibits a twisted conformation and extends from subdomain I to subdomain II (Fig. 2a). DIII is also a $\beta$-barrel structure. It contains in total 6 anti-parallel $\beta$-strands (A-F), assembling into an overall Ig-like fold. The inter-domain angles between DI-DII and DI-DIII were calculated to be $144.4^{\circ}$ and $153.6^{\circ}$, respectively. On the whole, the solved USUV-E structure is quite similar to those of other flaviviral $\mathrm{E}$ proteins [13, 20, 27, 29, 34, 39, 41].

We then characterized the possible dimeric architecture of USUV-E using our structure. As expected, a head-to-tail USUV-E dimer which resembles previously reported flaviviral pre-fusion E-dimers could be generated via simple symmetry operations (Fig. 2b). In this dimer form, the highly hydrophobic fusion loop is readily concealed from the bulk solvent by the DIII domain of the other molecule.

To further characterize the similarities and differences between our structure and other reported pre-fusion E crystal structures, those from DENV [28, 41, 57], JEV [26, 27], WNV [34], ZIKV [4, 13, 28, 51], and TBEV [39] (either in the free form or in the antibody-bound form) were selected and superimposed for structural comparison. While the DI and DIII domains could be well aligned, an astonishing oriental difference was observed for the DII domain such that it connects to DI in a more extended manner in USUV-E and therefore leads to an obviously enlarged inter-domain angle (Fig. 3a). This makes USUV-E an E protein with the largest DI-DII angle characterized thus far. To learn, in a more quantitative way, the observed domain-angle variations between DI and DII among these structures, the angle-difference was calculated for each structure pairs and then plotted in cluster for each structure group. As shown in Fig. 3b, in comparison to other E-structures which yield 


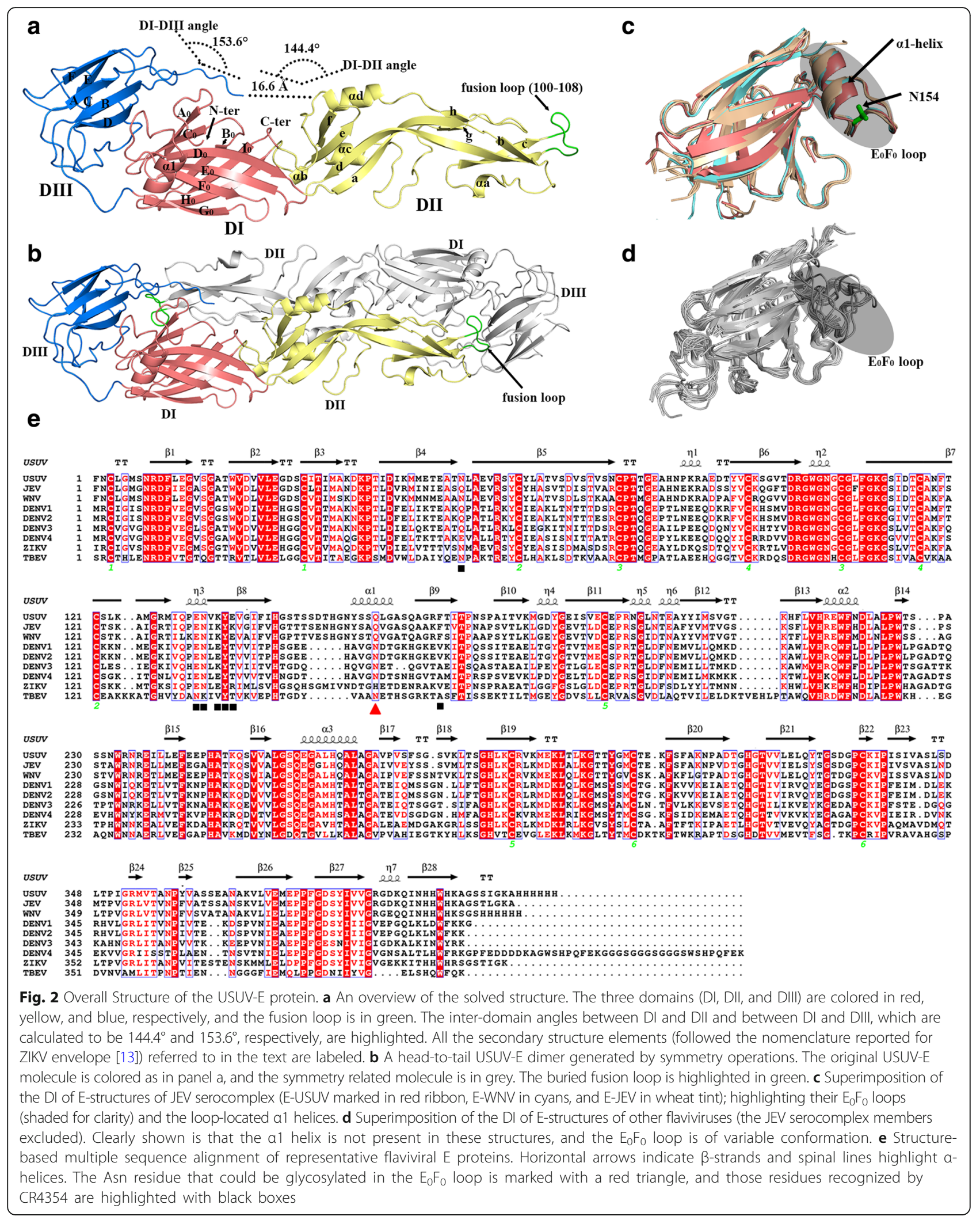




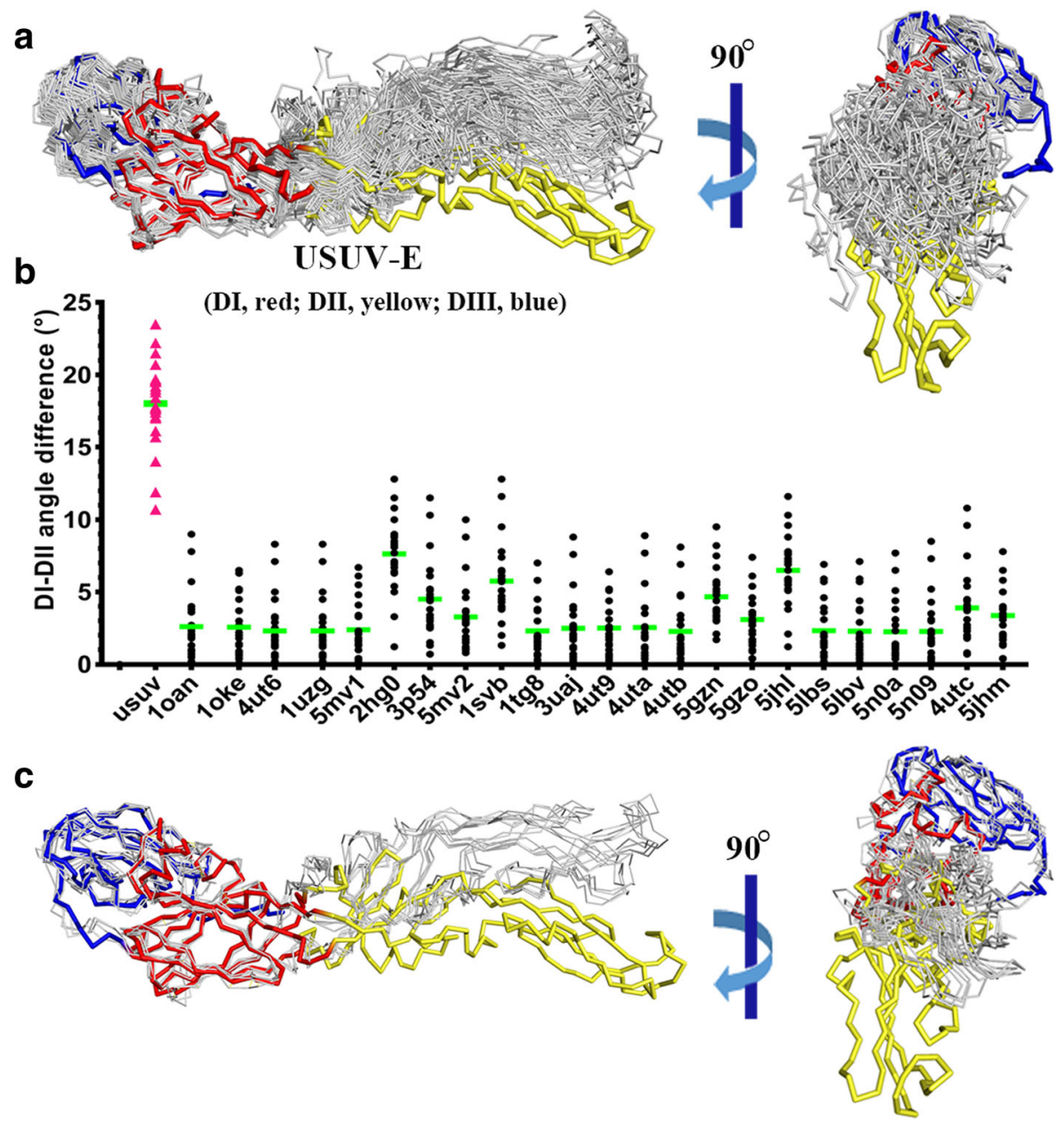

Fig. 3 Comparison of USUV-E structure with other reported crystal and cryo-EM pre-fusion flaviviral E-structures. a Superimposition of the crystal E-structures. The pre-fusion E-structures selected for comparison include those from DENV2 (PDB code: 1tg8, 1oan, 10ke, 4ut6, 4ut9, 4uta, 4utb, and 4utc), DENV3 (PDB code: 1uzg), DENV4 (PDB code: 3uaj), WNV (PDB code: 2hg0), JEV (PDB code: 3p54, 5mv1, $5 \mathrm{mv}$ ), TBEV (PDB code: 1svb), and ZIKV (PDB code: 5gzn, 5gzo, 5jhl, 5jhm, 5lbs, 5lbv, 5nOa, and 5n09). The USUV-E structure is colored red for Dl, yellow for DIl, and blue for DIII, respectively, and the rest E-structures are colored grey. The right panel is yielded by rotation of the structure for about $90^{\circ}$ around a vertical axis. Clearly shown is that while the DI and DIII domains could be well aligned, DII connects to DI in a more extended manner in USUV-E, resulting in an obviously enlarged inter-domain angle. b A quantitative comparison of the DI-DII domain-angle variations characterized in panel a. For each structure, its DI-DII domain-angle was compared to those of other structures, and the angle-difference was calculated for each structure pairs and then plotted as black dots. The angle-difference of USUV-E (relative to other flaviviral E proteins) was marked with red triangle. The mean values was represented with horizontal green lines. c Superimposition of our structure with representative cryo-EM pre-fusion E-structures including those from JEV (PDB code: 5ywo, 5wsn), ZIKV (PDB code: 6co8), and DENV-2 (PDB code: 3J27). The molecules are oriented and colored the same as in panel a

angle-differences ranging from $\sim 0-12.8^{\circ}$ (with an average ranging from $\sim 3-7.8^{\circ}$ ), a much higher degree of variations was observed for USUV-E (with angle-differences ranging from $\sim 10.7-23.5^{\circ}$ and an average of $\sim$ $\left.18^{\circ}\right)$. It is notable that such domain-angle variations between DI and DII have been widely observed in crystal structures of flaviviral E proteins, for which the crystal packing forces might also play a role. We therefore selected the cryo-EM structures of JEV [38, 52], ZIKV [43], and a representative dengue virus (DENV-2) [56] for a similar domain-angle comparison. Similar to those observed with the E crystal structures,
USUV-E is also the most extended pre-fusion structure analyzed in this study (Fig. 3c). We also noted that four His residues of the fusion tag are also traceable in our structure and extend towards DII. Nevertheless, these amino acids are far away ( $16.6 \AA$ ) (Fig. 2a) from physically interacting with DII residues and are unlikely the reason causing the increased DI-DII angle. We therefore believe the enlarged domain-angle between DI and DII in USUV-E is an intrinsic structural feature of this viral protein. It should be noted that the inter-domain motion is commonly observed in flaviviral $E$ proteins and has been proposed as a 
prerequisite for the pre-fusion to post-fusion transitions [37, 44]. Nevertheless, the DI-DII angle-difference as high as shown for the USUV-E structure reported in this study has not been observed previously. We believe this may represent potential evidence for a remarkable DI-DII domain-angle plasticity among flaviviruses. Our structure also indicates a notion that flaviviruses have evolved to adjust to accommodate species-specific dimeric arrangements featured with their variant DI-DII domain-angles.

Finally, a couple of potent neutralizing monoclonal antibodies (mAbs) against JEV and WNV, including A3, B2, E3, E113, NARMA3, 503, and CR4354, have been reported [12, $18,22,30,35,50,55]$. It is notable that among these, CR4354 recognizes E-epitopes locating in the DI-DII hinge region [21, 50]. We noticed that the hinge-residues recognized by CR4354 are largely preserved in USUV-E (Fig. 2e). Nevertheless, the observed enlarged DI-DII domain-angle of the USUV protein raises the possibility that these amino acids might occupy variant steric locations. It is therefore worth studying in the future to learn if CR4354 (or any other JEV serocomplex mAbs that target the DI-DII hinge region) could also be potentially used to prevent USUV infections.

\section{Abbreviations \\ DENV: Dengue virus; DI/DII/DIII: Domainl/Domainll/DomainIII; E: Envelope; IPTG: Isopropylthiogalactoside; JEV: Japanese encephalitis virus; MVEV: Murray Valley encephalitis virus; prM: pre-Membrane; SSRF: Shanghai Synchrotron Radiation Facility; TBEV: Tick-born encephalitis virus; USUV: Usutu virus; WNV: West Nile virus; ZIKV: Zika virus}

\section{Acknowledgements}

We thank the staff of BL18U1 beamline at National Center for Protein Sciences Shanghai and Shanghai Synchrotron Radiation Facility (Shanghai, People's Republic of China) for assistance during data collection.

\section{Funding}

This work was supported by the National Key R\&D Program of China (Grant No. 2016YFC1200305), the National Natural Science Foundation of China (Grant Nos. 81522026 and 31570157), the Sichuan Outstanding Youth Science \& Technology Funding (Grant No. 2016JQ0001), and the Outstanding Youth Foundation of Sichuan University (Grant No. 2016SCU04B01).

\section{Availability of data and materials}

All relevant information is provided in this current manuscript.

\section{Authors' contributions}

GL and ZMC contributed to the study conception and design. ZMC performed the experiment and data analysis. FY, SL, FY, YC were involved in data collection and structure determination. GL and ZMC wrote the manuscript, ZJC and YC checked and revised it. All authors read and approved the final manuscript.

\section{Ethics approval and consent to participate}

Not applicable.

\section{Consent for publication}

All the authors consent to publish.

\section{Competing interests}

The authors declare that they have no competing interests.

\section{Publisher's Note}

Springer Nature remains neutral with regard to jurisdictional claims in published maps and institutional affiliations.

\section{Author details}

'West China Hospital Emergency Department (WCHED), State Key Laboratory of Biotherapy, West China Hospital, Sichuan University, Chengdu 610041, Sichuan, China. ${ }^{2}$ Disaster Medicine Center, Sichuan University, Chengdu 610041, Sichuan, China.

Received: 29 July 2018 Accepted: 8 November 2018 Published online: 26 November 2018

\section{References}

1. Allering $L$, Jost $H$, Emmerich $P$, et al. Detection of Usutu virus infection in a healthy blood donor from south-west Germany, 2012. Euro Surveill. 2012; bulletin 17.

2. Bakonyi T, Erdelyi K, Brunthaler R, et al. Usutu virus, Austria and Hungary, 2010-2016. Emerg Microbes Infect. 2017;6:e85. https://doi.org/ 10.1038/emi.2017.72.

3. Bakonyi T, Gould EA, Kolodziejek J, et al. Complete genome analysis and molecular characterization of Usutu virus that emerged in Austria in 2001: comparison with the south African strain SAAR-1776 and other flaviviruses. Virology. 2004;328:301-10. https://doi.org/10.1016/.jvirol.2004.08.005.

4. Barba-Spaeth G, Dejnirattisai W, Rouvinski A, et al. Structural basis of potent Zika-dengue virus antibody cross-neutralization. Nature. 2016;536:48-53. https://doi.org/10.1038/nature18938.

5. Bazanow B, Jansen van Vuren P, Szymanski P, et al. A survey on West Nile and Usutu viruses in horses and birds in Poland. Viruses. 2018;10. https://doi. org/10.3390/v10020087.

6. Blazquez $A B$, Escribano-Romero E, Merino-Ramos T, et al. Infection with Usutu virus induces an autophagic response in mammalian cells. PLoS Negl Trop Dis. 2013;7:e2509. https://doi.org/10.1371/journal.pntd.0002509.

7. Bressanelli S, Stiasny K, Allison SL, et al. Structure of a flavivirus envelope glycoprotein in its low-pH-induced membrane fusion conformation. EMBO J. 2004;23:728-38. https://doi.org/10.1038/sj.emboj.7600064.

8. Cadar D, Becker N, Campos Rde M, et al. Usutu virus in bats, Germany, 2013 Emerg Infect Dis. 2014;20:1771-3. https://doi.org/10.3201/eid2010.140909.

9. Calisher $\mathrm{CH}$, Gould EA. Taxonomy of the virus family Flaviviridae. Adv Virus Res. 2003;59:1-19.

10. Calzolari M, Gaibani P, Bellini R, et al. Mosquito, bird and human surveillance of West Nile and Usutu viruses in Emilia-Romagna region (Italy) in 2010 PLoS One. 2012;7:e38058. https://doi.org/10.1371/journal.pone.0038058.

11. Cockburn JJ, Navarro Sanchez ME, Goncalvez AP, et al. Structural insights into the neutralization mechanism of a higher primate antibody against dengue virus. EMBO J. 2012;31:767-79. https://doi.org/10.1038/emboj.2011.439.

12. Crill WD, Chang GJ. Localization and characterization of flavivirus envelope glycoprotein cross-reactive epitopes. J Virol. 2004;78:13975-86. https://doi. org/10.1128/jvi.78.24.13975-13986.2004.

13. Dai L, Song J, Lu X, et al. Structures of the Zika virus envelope protein and its complex with a Flavivirus broadly protective antibody. Cell Host Microbe. 2016;19:696-704. https://doi.org/10.1016/j.chom.2016.04.013.

14. Debreczeni JE, Emsley P. Handling ligands with coot. Acta Crystallogr D Biol Crystallogr. 2012;68:425-30. https://doi.org/10.1107/s0907444912000200.

15. Emsley P, Cowtan K. Coot: model-building tools for molecular graphics. Acta Crystallogr D Biol Crystallogr. 2004;60:2126-32. https://doi.org/10.1107/ s0907444904019158.

16. Fernandes $P$, Barois $P$, Wang $S T$, et al. Polarization studies of resonant forbidden reflections in liquid crystals. Phys Rev Lett. 2007:99:227801. https://doi.org/10.1103/PhysRevLett.99.227801.

17. Gaibani P, Cavrini F, Gould EA, et al. Comparative genomic and phylogenetic analysis of the first Usutu virus isolate from a human patient presenting with neurological symptoms. PLoS One. 2013;8:e64761. https:// doi.org/10.1371/journal.pone.0064761

18. Goncalvez AP, Chien $\mathrm{CH}$, Tubthong $\mathrm{K}$, et al. Humanized monoclonal antibodies derived from chimpanzee Fabs protect against Japanese encephalitis virus in vitro and in vivo. J Virol. 2008;82:7009-21. https://doi. org/10.1128/jvi.00291-08.

19. Grottola A, Marcacci M, Tagliazucchi S, et al. Usutu virus infections in humans: a retrospective analysis in the municipality of Modena, Italy. Clin Microbiol Infect. 2017;23:33-7. https://doi.org/10.1016/j.cmi.2016.09.019. 
20. Kanai R, Kar K, Anthony K, et al. Crystal structure of west nile virus envelope glycoprotein reveals viral surface epitopes. J Virol. 2006;80:11000-8. https:// doi.org/10.1128/jvi.01735-06.

21. Kaufmann B, Vogt MR, Goudsmit J, et al. Neutralization of West Nile virus by cross-linking of its surface proteins with fab fragments of the human monoclonal antibody CR4354. Proc Natl Acad Sci U S A. 2010;107:18950-5. https://doi.org/10.1073/pnas.1011036107.

22. Kobayashi $Y$, Hasegawa H, Yamauchi T. Studies on the antigenic structure of Japanese encephalitis virus using monoclonal antibodies. Microbiol Immunol. 1985:29:1069-82.

23. Kuno G, Chang GJ, Tsuchiya KR, et al. Phylogeny of the genus Flavivirus. J Virol. 1998;72:73-83.

24. Laskowski RA, Rullmannn JA, MacArthur MW, et al. AQUA and PROCHECKNMR: programs for checking the quality of protein structures solved by NMR. J Biomol NMR. 1996:8:477-86.

25. Liu J, Dai L, Qi J, et al. Diverse peptide presentation of rhesus macaque major histocompatibility complex class I Mamu-a 02 revealed by two peptide complex structures and insights into immune escape of simian immunodeficiency virus. J Virol. 2011;85:7372-83. https://doi.org/10.1128/jvi.00350-11.

26. Liu X, Zhao X, Na R, et al. The structure differences of Japanese encephalitis virus SA14 and SA14-14-2 E proteins elucidate the virulence attenuation mechanism. Protein Cell. 2018. https://doi.org/10.1007/s13238-018-0551-6.

27. Luca VC, AbiMansour J, Nelson CA, et al. Crystal structure of the Japanese encephalitis virus envelope protein. J Virol. 2012;86:2337-46. https://doi.org/ 10.1128/jvi.06072-11.

28. Modis Y, Ogata S, Clements D, et al. A ligand-binding pocket in the dengue virus envelope glycoprotein. Proc Natl Acad Sci U S A. 2003;100:6986-91. https://doi.org/10.1073/pnas.0832193100.

29. Modis Y, Ogata S, Clements D, et al. Variable surface epitopes in the crystal structure of dengue virus type 3 envelope glycoprotein. J Virol. 2005;79: 1223-31. https://doi.org/10.1128/JVI.79.2.1223-1231.2005.

30. Morita K, Tadano M, Nakaji S, et al. Locus of a virus neutralization epitope on the Japanese encephalitis virus envelope protein determined by use of long PCR-based region-specific random mutagenesis. Virology. 2001;287: 417-26. https://doi.org/10.1006/viro.2001.1048.

31. Murshudov GN, Skubak P, Lebedev AA, et al. REFMAC5 for the refinement of macromolecular crystal structures. Acta Crystallogr D Biol Crystallogr. 2011:67:355-67. https://doi.org/10.1107/s0907444911001314.

32. Nikolay B, Diallo M, Boye CS, et al. Usutu virus in Africa. Vector Borne Zoonotic Dis. 2011;11:1417-23. https://doi.org/10.1089/vbz.2011.0631.

33. Nikolay B, Dupressoir A, Firth C, et al. Comparative full length genome sequence analysis of Usutu virus isolates from Africa. Virol J. 2013;10:217. https://doi.org/10.1186/1743-422x-10-217.

34. Nybakken GE, Nelson CA, Chen BR, et al. Crystal structure of the West Nile virus envelope glycoprotein. J Virol. 2006;80:11467-74. https://doi.org/10. 1128/JVI.01125-06

35. Oliphant T, Nybakken GE, Engle M, et al. Antibody recognition and neutralization determinants on domains I and II of West Nile virus envelope protein. J Virol. 2006;80:12149-59. https://doi.org/10.1128/jvi.01732-06.

36. Otwinowski Z, Minor W. [20] processing of X-ray diffraction data collected in oscillation mode. Methods Enzymol. 1997;276:307-26. https://doi.org/10. 1016/s0076-6879(97)76066-X.

37. Perera R, Khaliq M, Kuhn RJ. Closing the door on flaviviruses: entry as a target for antiviral drug design. Antivir Res. 2008;80:11-22. https://doi.org/10. 1016/j.antiviral.2008.05.004.

38. Qiu $X$, Lei $Y$, Yang $P$, et al. Structural basis for neutralization of Japanese encephalitis virus by two potent therapeutic antibodies. Nature microbiology. 2018;3:287-94. https://doi.org/10.1038/s41564-017-0099-x.

39. Rey FA, Heinz FX, Mandl C, et al. The envelope glycoprotein from tick-borne encephalitis virus at 2 a resolution. Nature. 1995;375:291-8. https://doi.org/ 10.1038/375291a0

40. Rouvinski A, Dejnirattisai W, Guardado-Calvo P, et al. Covalently linked dengue virus envelope glycoprotein dimers reduce exposure of the immunodominant fusion loop epitope. Nat Commun. 2017;8:15411. https:// doi.org/10.1038/ncomms15411

41. Rouvinski A, Guardado-Calvo P, Barba-Spaeth G, et al. Recognition determinants of broadly neutralizing human antibodies against dengue viruses. Nature. 2015;520:109-13. https://doi.org/10.1038/nature14130.

42. Salinas S, Constant O, Desmetz C, et al. Deleterious effect of Usutu virus on human neural cells. PLoS Negl Trop Dis. 2017;11:e0005913. https://doi.org/ 10.1371/journal.pntd.0005913.
43. Sevvana M, Long F, Miller AS, et al. Refinement and Analysis of the Mature Zika Virus Cryo-EM Structure at 3.1 A Resolution. Structure. 2018;26:11691177.e1163. https://doi.org/10.1016/j.str.2018.05.006.

44. Smit JM, Moesker B, Rodenhuis-Zybert I, et al. Flavivirus cell entry and membrane fusion. Viruses. 2011;3:160-71. https://doi.org/10.3390/v3020160.

45. Steinmetz HW, Bakonyi T, Weissenbock $H$, et al. Emergence and establishment of Usutu virus infection in wild and captive avian species in and around Zurich, Switzerland--genomic and pathologic comparison to other central European outbreaks. Vet Microbiol. 2011;148:207-12. https:// doi.org/10.1016/j.vetmic.2010.09.018.

46. Tamba M, Bonilauri $P$, Bellini $R$, et al. Detection of Usutu virus within a West Nile virus surveillance program in Northern Italy. Vector Borne Zoonotic Dis. 2011;11:551-7. https://doi.org/10.1089/vbz.2010.0055.

47. Terwilliger TC, Grosse-Kunstleve RW, Afonine PV, et al. Iterative model building, structure refinement and density modification with the PHENIX AutoBuild wizard. Acta Crystallogr D Biol Crystallog. 2008;64:61-9. https:// doi.org/10.1107/s090744490705024x.

48. Vazquez A, Jimenez-Clavero M, Franco L, et al. Usutu virus: potential risk of human disease in Europe. Euro Surveill. 2011a;bulletin 16.

49. Vazquez A, Ruiz S, Herrero L, et al. West Nile and Usutu viruses in mosquitoes in Spain, 2008-2009. Am J Trop Med Hyg. 2011b;85:178-81. https://doi.org/10.4269/ajtmh.2011.11-0042.

50. Vogt MR, Moesker B, Goudsmit J, et al. Human monoclonal antibodies against West Nile virus induced by natural infection neutralize at a postattachment step. J Virol. 2009;83:6494-507. https://doi.org/10.1128/ jvi.00286-09.

51. Wang Q, Yang H, Liu X, et al. Molecular determinants of human neutralizing antibodies isolated from a patient infected with Zika virus. Sci Transl Med. 2016;8:369ra179. https://doi.org/10.1126/scitransImed.aai8336.

52. Wang X, Li SH, Zhu L, et al. Near-atomic structure of Japanese encephalitis virus reveals critical determinants of virulence and stability. Nat Commun. 2017;8:14. https://doi.org/10.1038/s41467-017-00024-6.

53. Weissenbock H, Bakonyi T, Rossi G, et al. Usutu virus, Italy, 1996. Emerg Infect Dis. 2013;19:274-7. https://doi.org/10.3201/eid1902.121191.

54. Weissenbock H, Kolodziejek J, Url A, et al. Emergence of Usutu virus, an African mosquito-borne flavivirus of the Japanese encephalitis virus group, Central Europe. Emerg Infect Dis. 2002;8:652-6. https://doi.org/10.3201/ eid0807.020094

55. Wu KP, Wu CW, Tsao YP, et al. Structural basis of a flavivirus recognized by its neutralizing antibody: solution structure of the domain III of the Japanese encephalitis virus envelope protein. J Biol Chem. 2003:278:4600713. https://doi.org/10.1074/jbc.M307776200.

56. Zhang $X$, Ge $P, Y u$, et al. Cryo-EM structure of the mature dengue virus at 3.5-a resolution. Nat Struct Mol Biol. 2013;20:105-10. https://doi. org/10.1038/nsmb.2463

57. Zhang Y, Zhang W, Ogata S, et al. Conformational changes of the flavivirus E glycoprotein. Structure. 2004;12:1607-18. https://doi.org/10. 1016/j.str.2004.06.019

58. Zwart PH, Afonine PV, Grosse-Kunstleve RW, et al. Automated structure solution with the PHENIX suite. Methods Mol Biol. 2008;426:419-35. https:// doi.org/10.1007/978-1-60327-058-8_28.

\section{Ready to submit your research? Choose BMC and benefit from:}

- fast, convenient online submission

- thorough peer review by experienced researchers in your field

- rapid publication on acceptance

- support for research data, including large and complex data types

- gold Open Access which fosters wider collaboration and increased citations

- maximum visibility for your research: over $100 \mathrm{M}$ website views per year

At BMC, research is always in progress.

Learn more biomedcentral.com/submissions 